\title{
Prevalence of diarrhea and associated risk factors among children under-five years of age in Eastern Ethiopia: A cross-sectional study
}

\author{
Bezatu Mengistie $^{1 *}$, Yemane Berhane $^{2}$, Alemayehu Worku $^{2,3}$ \\ ${ }^{1}$ College of Health Sciences, Haramaya University, Harar, Ethiopia; ${ }^{*}$ Corresponding Author: bezex2000@yahoo.com \\ ${ }^{2}$ Addis Continental Institute of Public Health, Addis Ababa, Ethiopia; yemanebrehane@addiscontinental.edu.et \\ ${ }^{3}$ School of Public Health, Addis Ababa University, Addis Ababa, Ethiopia; alemayehuwy@yahoo.com
}

Received 25 July 2013; revised 1 September 2013; accepted 21 September 2013

Copyright (C) 2013 Bezatu Mengistie et al. This is an open access article distributed under the Creative Commons Attribution License, which permits unrestricted use, distribution, and reproduction in any medium, provided the original work is properly cited.

\begin{abstract}
Diarrhea remains a major cause of mortality in children under 5 years of age in Sub-Saharan countries in Africa. Risk factors for diarrhea vary by context and have important implications for developing appropriate strategies to reduce the burden of the disease. The objective of this study was to assess the prevalence of diarrhea and associated risk factors among children under 5 years of age in Kersa district, located in Eastern Ethiopia. A community-based crosssectional study was conducted among 1456 randomly selected households with at least one child under 5 years of age. A questionnaire and an observational check list were used for collecting information on socio-economic characteristics, environmental hygiene and behavioral practices, and occurrence of diarrhea among children under 5 years of age. Logistic regression was used to calculate the adjusted odds ratio of $95 \%$ confidence interval. The two-week prevalence of diarrhea among children under 5 years of age was $22.5 \%$ (95\% Cl: $20.3-24.6)$. Improper refuse disposal practices $(O R=2.22$, $95 \% \mathrm{Cl}: 1.20-4.03)$, lack of hand washing facilities (OR $=1.92,95 \% \mathrm{Cl}: 1.29-2.86$ ), living in rural area (OR $=1.81,95 \% \mathrm{Cl}: 1.12-3.31)$, the presence of two or more siblings in a household (OR $=1.74,95 \% \mathrm{Cl}: 1.33-2.28$ ), and age of the child $(\mathrm{OR}=2.25,95 \% \mathrm{Cl}$; 1.5-3.36) were the major risk factors for diarrhea. This study demonstrated that diarrhea morbidity was relatively high among children under 5 years of age residing in Eastern Ethiopia. Efforts to reduce childhood diarrhea
\end{abstract}

${ }^{*}$ The authors declare that they have no competing interest. should focus on improving household sanitation, personal hygiene, and child birth spacing.

Keywords: Diarrhea; Risk Factor; Children under 5 Years; Ethiopia; Cross-Sectional Study; Hygiene

\section{INTRODUCTION}

Diarrhea remains the leading cause of morbidity and mortality in children under 5 years old worldwide. The burden is disproportionately high among children in lowand middle-income countries. Young children are especially vulnerable to diarrheal disease and a high proportion of the deaths occur in the first 2 years of life. Worldwide, the majority of deaths related to diarrhea take place in Africa and South Asia. Nearly half of deaths from diarrhea among young children occur in Africa where diarrhea is the largest cause of death among children under 5 years old and a major cause of childhood illness [1-4].

Although some of the factors associated with diarrhea in children in Ethiopia such as Acute Respiratory Infection (ARI), maternal history of recent diarrhea, maternal education, well source of water, obtaining water from storage container by dipping, availability of latrine facilities, living in a house with fewer number of rooms, not breast feeding, duration of breast feeding, and age of the child, have been identified, diarrhea is still a major public health problem among children under 5 years old [58].

Epidemiologic studies show that factors determining the occurrence of diarrhea in children are complex and the relative contribution of each factor varies as a function of interaction between socio-economic, environmental and behavioral variables [5,9-11]. Recent research indicated that studies in differing environment and 
prioritizing interventions based on context would be useful to prevent deaths from diarrhea [12]. In Ethiopia, despite the high prevalence of the disease, reports from population-based studies are sparse. The study would be helpful in planning and implementation of prevention strategies at the community level. Thus, the objective of this study was to assess the prevalence of diarrhea and associated factors among children of age under five.

\section{METHODS}

The study was conducted in Kersa Demographic Surveillance and Health Research Center (KDS-HRC) field site, located in Eastern Ethiopia in January 2011. The study site is approximately 482 kilometers from Addis Ababa, and it is divided into 2 urban and 10 rural kebeles (the smallest administrative unit in Ethiopia), with total population of 55,394 residents. Agriculture is the main source of the district's livelihood. Health services in the district are provided by six health centers and 28 health posts. At the kebele level, health care is delivered by extension workers who are assigned to render health services at the local level [13].

The sample size was calculated using the formula for estimation of single proportion [14], $n=Z^{2} * P(1-P) / r^{2}$. Where: $\mathrm{Z}$ value is 1.96: $\mathrm{P}$ is the prevalence of diarrhea among children under-five years old that was assumed to be $18 \%$ [15]; and $r$ is the margin error of estimation that was assumed to be $2 \%(0.02)$. This provided a sample size of 1417 children. To account for predicted 5\% nonresponse rate, the final sample was 1488 children.

Households with at least one child under 5years of age were eligible for the study. Study participants were selected using a simple random sampling technique from a sampling registry obtained from Kersa Demographic Surveillance and Health Research Center (KDS-HRC) registration book. For households with two or more children under 5 year of age, the index child was selected by a lottery method.

Data were collected using questionnaire tested previously and administered by an interviewer and the observational check list. The questionnaire was prepared based on the Multiple Indicator Cluster Survey (MICS), Demographic and Health Survey (DHS) and World Health Organization (WHO) core questionnaires related to diarrhea. The questionnaire was written in English, translated into Affan Oromo (local language), and then translated back into English to assure its accuracy. The respondents were primarily mothers of eligible children under 5 years of age, but in the absence of the mother, the next primary caregiver was interviewed.

Thirteen individuals who were trained, and experienced in the KDS-HRC questionnaire administration, and were fluent speakers of Affan Oromo collected the data. The data collection was supervised by 3 supervisors at the center. Their role was to daily check the consistency and completeness of the collected questionnaires and re-interview randomly selected $5 \%$ of the households to check the data quality. Trained data clerks double entered the data using EpiData 3.1 software.

The primary outcome variable was the occurrence of diarrhea in the 2-week period preceding data collection. The independent variables included socio-economic (residence, family size, caregiver's age, occupation, educational status, parental age, occupation, educational status, number of children under 5 years of age in the household and wealth), environmental (the availability of hand washing facility, latrine, type of and distance from water source, refuse and stool disposal) and behavioral and child-related (child feeding practice, measles vaccination, age and gender of the child) factors.

In this study, diarrhea was defined as the passage of three or more loose stools over 24 hours period or more frequently than normal for a child [16]. Water from protected springs and/or wells, from pipe and from distribution post was considered as improved source [17]. Disposal of child's stool was considered proper if the stool was put into the latrine or buried. The economic status of the households was categorized into poor, middle and better off using wealth index, which was calculated from the households' assets using principal component analysis [18].

Descriptive statistics were used to summarize the study variables. Logistic regression analysis was performed separately for three variable blocks estimated the effect socio-economic, environmental, and behavioral and child related factors. The final model estimated the overall effect of the three blocks of variables. All models used simultaneous entry procedure to select the significant determinants and adjusted for confounding factors. All data were analyzed using SPSS v.16 statistical software (IBM SPSS, Almaden, NY, US).

To reduce excessive number of variables and resulting instability of the model, only variables with significance $\mathrm{P}<0.1$ in the bivariate analysis were considered for inclusion in the multivariable analysis. Variables with $\mathrm{P}<$ 0.05 in the multivariable analysis were considered significant. Multi-colinearity of variables was assessed by calculating Variance Inflation Factor (VIF).

The study was approved by the Ethic Committee at the College of Health and Medical Sciences of Haramaya University. Mothers or caregivers of children were informed about the study and its objectives before enrollment. A written informed consent was obtained from the mother or caregiver of each participating child. All collected records were kept confidential. 


\section{RESULT}

A total of 1456 households participated in the study with a response rate of $97.8 \%$. Almost all respondents were biological mothers (98.4\%), married (97.3\%) and housewives (96.7\%), most had no formal education $(82.2 \%)$ and were from rural area $(85.3 \%)$. Mean children age was $26.6 \pm 13.5$ months. There was slightly more male $(51.9 \%)$ than female children $(51.9 \%$ and $48.1 \%)$.

Out of 1456 children, 327 had diarrhea two weeks before the interview, provided a prevalence of $22.5 \%$ [ $95 \%$ confidence interval (CI) $20.3 \%-24.6 \%$ ]. Children in the age group 6-11 months had the highest prevalence of diarrhea followed by the age groups $12-23$ months. The distribution of prevalence of diarrhea by socio-economic, environmental and behavioral characteristics is

\section{shown in Tables 1-3.}

\section{Factors Associated with Diarrhea}

Multivariate analyses were carried out to identifythe risk factors associated with diarrhea. In the first block logistic regression model, diarrhea was significantly higher among children living in the rural than urban area. In the second model, childhood diarrhea was significantly associated with lack of hand washing facility, domestic water supply from unimproved sources and open dumping of refuse around the house. In the third model, diarrhea was significantly associated with age of the child and number of under-five children in the household.

In the final logistic regression model, diarrhea was independently associated with open dumping of refuse,

Table 1. Socio-economic determinants of diarrhea among children under 5 years of age in Kersa District, Eastern Ethiopia, 2011.

\begin{tabular}{|c|c|c|c|}
\hline \multirow{2}{*}{ Variables } & \multicolumn{2}{|c|}{ Diarrhea $(\mathrm{N}=1456)$} & \multirow[t]{2}{*}{$\mathrm{COR}(95 \%) \mathrm{CI}$} \\
\hline & Yes & No & \\
\hline \multicolumn{4}{|l|}{ Residence } \\
\hline Urban & 27 & 188 & 1 \\
\hline Rural & 300 & 941 & $2.22(1.45-3.39)$ \\
\hline \multicolumn{4}{|l|}{ Age of mother/caregiver } \\
\hline $15-24$ & 70 & 194 & $0.75(0.55-1.02)$ \\
\hline $25-34$ & 211 & 778 & $0.81(0.53-1.24)$ \\
\hline$>34$ & 46 & 157 & 1 \\
\hline \multicolumn{4}{|c|}{ Education of mother/caregiver } \\
\hline No formal education & 284 & 950 & $1.30(0.88-1.81)$ \\
\hline Primary and above & 42 & 179 & 1 \\
\hline \multicolumn{4}{|c|}{ Occupation of mother/caregiver } \\
\hline Housewife & 317 & 1091 & $1.10(0.54-2.24)$ \\
\hline Other & 10 & 38 & 1 \\
\hline \multicolumn{4}{|l|}{ Education of father } \\
\hline No formal education & 197 & 719 & $1.15(0.89-1.49)$ \\
\hline Primary and above & 130 & 410 & 1 \\
\hline \multicolumn{4}{|c|}{ Family size (persons per household) } \\
\hline$>4$ & 233 & 731 & $1.35(1.03-1.76)$ \\
\hline \multicolumn{4}{|l|}{ Wealth index } \\
\hline Low & 112 & 373 & $1.09(0.8-1.50)$ \\
\hline Middle & 106 & 379 & $1.03(0.93-1.41)$ \\
\hline Better off & 101 & 385 & 1 \\
\hline
\end{tabular}


Table 2. Environmental exposure variables associated with diarrhea among children under 5 years of age in Kersa district, Eastern Ethiopia, 2011.

\begin{tabular}{|c|c|c|c|}
\hline \multirow{2}{*}{ Variables } & \multicolumn{2}{|c|}{ Diarrhea } & \multirow[t]{2}{*}{$\operatorname{COR}(95 \%) \mathrm{CI}$} \\
\hline & Yes & No & \\
\hline \multicolumn{4}{|l|}{ Availability of latrine } \\
\hline Yes & 68 & 325 & 1 \\
\hline No & 259 & 804 & $1.54(1.14-2.07)$ \\
\hline \multicolumn{4}{|c|}{ Availability of hand washing facilities } \\
\hline Yes & 40 & 254 & 1 \\
\hline No & 287 & 875 & $2.08(1.45-2.98)$ \\
\hline \multicolumn{4}{|c|}{ Main source of domestic water } \\
\hline Improved & 194 & 761 & 1 \\
\hline Unimproved & 133 & 368 & $1.41(1.10-1.82)$ \\
\hline \multicolumn{4}{|l|}{ Separate room for cooking } \\
\hline Yes & 163 & 589 & 1 \\
\hline No & 164 & 540 & $1.09(0.85-1.40)$ \\
\hline \multicolumn{4}{|l|}{ Refuse disposal } \\
\hline Waste Pit/burning & 57 & 275 & 1 \\
\hline Open dumping & 27 & 39 & $3.34(1.89-5.89)$ \\
\hline Used for manure & 241 & 813 & $1.43(1.03-1.96)$ \\
\hline \multicolumn{4}{|l|}{ Child stool disposal } \\
\hline Proper & 106 & 441 & 1 \\
\hline Improper & 221 & 688 & $1.33(1.03-1.73)$ \\
\hline \multicolumn{4}{|c|}{ Time to obtain drinking water (round trip) } \\
\hline$<15$ minutes & 118 & 472 & 1 \\
\hline $15-30$ minutes & 117 & 392 & $1.19(0.89-1.59)$ \\
\hline More than 30 minutes & 92 & 265 & $1.38(1.01-1.89)$ \\
\hline \multicolumn{4}{|l|}{ Number of sleeping rooms } \\
\hline One & 299 & 965 & $1.81(1.19-2.76)$ \\
\hline Two and more & 28 & 164 & 1 \\
\hline
\end{tabular}

lack of hand washing facility, rural residence, and number of siblings under 5 years in a household and age of the child. More specifically, children in the households who open dumped refuse around the house had 2.22 times higher odds of having diarrhea compared to children in the households who used a waste disposal pit $(\mathrm{OR}=2.22,95 \% \mathrm{CI} 1.2-4.03)$. The odds of diarrhea was 1.74 times higher in children from the households with two or more siblings compared to children in the households with only one sibling (OR $=1.74,95 \%$ CI 1.33 2.28). Children in the households without hand washing facilities had 1.92 times higher odds of having diarrhea compared to children in the households with no hand washing facility $(\mathrm{OR}=1.92,95 \% \mathrm{CI} 1.29$ - 2.86) (Table 4).

\section{DISCUSSION}

This study investigated the prevalence and socioeconomic, environmental and behavioral risk factors of diarrhea morbidity in children $<5$ years old in Eastern Ethiopia. The two-week prevalence of diarrhea among the children was $22.5 \%$ (95\% CI: 20.3 - 24.6). The occurrence 
Table 3. Behavioral, child and care related risk factors for diarrhea among children under 5 years of age, Kersa District, Eastern Ethiopia, 2011.

\begin{tabular}{|c|c|c|c|}
\hline \multirow{2}{*}{ Variables } & \multicolumn{2}{|c|}{ Diarrhea } & \multirow[t]{2}{*}{$\operatorname{COR}(95 \%) \mathrm{CI}$} \\
\hline & Yes & No & \\
\hline \multicolumn{4}{|c|}{ Bottle feeding $(\mathrm{n}=737)$} \\
\hline Yes & 36 & 104 & $1.05(0.68-1.59)$ \\
\hline No & 159 & 438 & 1 \\
\hline \multicolumn{4}{|c|}{ Currently breast feeding $(\mathrm{n}=737)$} \\
\hline Yes & 140 & 417 & 1 \\
\hline No & 55 & 125 & $1.31(0.90-1.89)$ \\
\hline \multicolumn{4}{|c|}{ Duration of breast feeding $(n=737)$} \\
\hline$<1$ year & 121 & 345 & $1.07(0.76-1.5)$ \\
\hline$\geq 1$ year & 74 & 197 & 1 \\
\hline \multicolumn{4}{|c|}{ Feeding children soon after food preparation } \\
\hline Yes & 204 & 668 & $1.14(0.88-1.47)$ \\
\hline No & 123 & 461 & 1 \\
\hline \multicolumn{4}{|c|}{ Serving uncooked food to children } \\
\hline Yes & 50 & 203 & $0.82(0.58-1.15)$ \\
\hline No & 277 & 926 & 1 \\
\hline \multicolumn{4}{|c|}{ Measles vaccination $(\mathrm{n}=1302)$} \\
\hline Yes & 163 & 610 & 1 \\
\hline No & 130 & 399 & $1.21(0.93-1.58)$ \\
\hline \multicolumn{4}{|l|}{ Child sex } \\
\hline Male & 166 & 590 & 1 \\
\hline Female & 161 & 539 & $1.06(0.83-1.35)$ \\
\hline \multicolumn{4}{|c|}{ Number of under 5 sibling per household } \\
\hline One & 144 & 698 & 1 \\
\hline Two and more & 183 & 431 & $2.05(1.60-2.64)$ \\
\hline \multicolumn{4}{|c|}{ Child age (in months) } \\
\hline $0-5$ & 4 & 47 & $0.40(0.14-1.15)$ \\
\hline $6-11$ & 61 & 114 & $2.54(1.73-3.73)$ \\
\hline $12-23$ & 86 & 223 & $1.83(1.31-2.56)$ \\
\hline $24-35$ & 84 & 308 & $1.29(0.93-1.80)$ \\
\hline$>35$ & 92 & 437 & 1 \\
\hline
\end{tabular}

*Measles vaccination is calculated for children 9 months and above; *bottle feeding and breast feeding is calculated for children $<2$ years of age.

of diarrhea was positively associated with rural residence, aged 6 to 23 months, open dumping of refuse around the house, lack of hand washing facility and presence two or more children under $<5$ years old in the household.

The two-week period of diarrhea occurrence used as a criterion in our study is comparable with studies conducted in Western Ethiopia [5], Egypt [19] and India [20]. Such high rate of childhood diarrhea, despite considerable improvements in water sources and sanitation facilities, indicates the need for more attention. 
Table 4. Multivariable analysis of risk factors of diarrhea among children under 5 years of age in Kersa district, Eastern Ethiopia, 2011 .

\begin{tabular}{|c|c|c|c|c|}
\hline Risk factors & $\begin{array}{c}\text { Model I } \\
\text { AOR }(95 \% \text { CI })\end{array}$ & $\begin{array}{c}\text { Model II } \\
\text { AOR }(95 \% \text { CI) }\end{array}$ & $\begin{array}{c}\text { Model III } \\
\text { AOR }(95 \% \mathrm{CI})\end{array}$ & $\begin{array}{c}\text { Final model } \\
\text { AOR }(95 \% \mathrm{CI})\end{array}$ \\
\hline \multicolumn{5}{|l|}{ Area of residence } \\
\hline Urban & 1 & & & 1 \\
\hline Rural & $2.15(1.35-3.43)^{*}$ & & & $1.81(1.12-3.31)^{*}$ \\
\hline \multicolumn{5}{|l|}{ Education mother/caretaker } \\
\hline No formal education & $1.14(0.76-1.69)$ & & & $1.23(0.79-1.92)$ \\
\hline Primary and above & 1 & & & 1 \\
\hline \multicolumn{5}{|l|}{ Family size } \\
\hline$\leq 4$ & 1 & & & 1 \\
\hline$>4$ & $1.30(0.98-1.71)$ & & & $1.13(0.84-1.51)$ \\
\hline \multicolumn{5}{|l|}{ Availability of latrine facility } \\
\hline Yes & & 1 & & 1 \\
\hline No & & $1.13(0.77-1.67)$ & & $1.14(0.75-1.73)$ \\
\hline \multicolumn{5}{|l|}{ Availability of hand washing facility } \\
\hline Yes & & 1 & & 1 \\
\hline No & & $1.80(1.22-2.66)^{*}$ & & $1.92(1.29-2.86)^{*}$ \\
\hline Main source of domestic water & & 1 & & 1 \\
\hline \multicolumn{5}{|l|}{ Improved } \\
\hline Unimproved & & $1.35(1.02-1.80)^{*}$ & & $1.16(0.86-1.55)$ \\
\hline \multicolumn{5}{|l|}{ Time to fetch water (round trip) } \\
\hline$<15$ minutes & & 1 & & 1 \\
\hline $15-30$ minutes & & $1.03(0.75-1.40)$ & & $1.02(0.72-1.44)$ \\
\hline More than 30 minutes & & $1.06(0.74-1.51)$ & & $1.04(0.71-1.51)$ \\
\hline \multicolumn{5}{|l|}{ Refuse disposal } \\
\hline Waste pit/burning & & 1 & & 1 \\
\hline Open dumping & & $2.68(1.51-4.79)^{*}$ & & $2.22(1.20-4.03)^{*}$ \\
\hline Used for manure & & $1.22(0.87-1.72)$ & & $1.12(0.77-1.60)$ \\
\hline \multicolumn{5}{|l|}{ Child stool disposal } \\
\hline Proper & & 1 & & 1 \\
\hline Improper & & $1.23(0.88-1.70)$ & & $1.29(0.92-1.81)$ \\
\hline \multicolumn{5}{|l|}{ Number of sleeping rooms } \\
\hline One & & $1.43(0.88-1.70)$ & & $1.40(0.91-2.20)$ \\
\hline Two or more & & 1 & & 1 \\
\hline \multicolumn{5}{|c|}{ Number of children under 5 in the household } \\
\hline One & & & 1 & 1 \\
\hline Two or more & & & $1.93(1.5-2.49)^{*}$ & $1.74(1.33-2.28)^{*}$ \\
\hline \multicolumn{5}{|l|}{ Child age (months) } \\
\hline $0-5$ & & & $0.39(0.13-1.11)$ & $0.36(0.12-1.04)$ \\
\hline $6-11$ & & & $2.31(1.56-3.41)^{*}$ & $2.25(1.50-3.36)^{*}$ \\
\hline $12-23$ & & & $1.71(1.22-2.4)^{*}$ & $1.83(1.29-2.60)^{*}$ \\
\hline $24-35$ & & & $1.30(0.99-1.81)$ & $1.34(0.95-1.88)$ \\
\hline$>35$ & & & 1 & 1 \\
\hline
\end{tabular}

$*=\mathrm{P}<0.05$. 
The importance of refuse in transmitting diarrhea pathogens has been documented [21]. In our study, open disposal of refuse around the house was an independent risk factor for diarrhea. This is in agreement with other studies conducted elsewhere $[22,23]$. The simple explanation might be that inappropriate disposal of refuse provides breeding site for insects, which may carry diarrhea pathogens from the refuse to water and food.

Studies showed the importance of hand washing in reducing the occurrence of childhood diarrhea [24,25]. However, monitoring correct hand washing behavior at critical times is challenging. Hygiene behavior related observational studies showed wide discrepancy between what people said and did and suggested that reported hand washing behavior over estimate observed behavior [26-28] and supported the availability of water and soap in places of hand washing as indicator of hand washing behavior [29]. In this study, there was a significant positive association between the availability of hand washing facility with childhood diarrhea.

The study showed that diarrhea was significantly associated with children in the age groups 6 - 11 months and 12 - 23 months compared to children aged above 35 months. This finding is in agreement with other studies $[5,9]$. The peak prevalence of diarrhea at the age of $6-11$ months can be explained by the introduction of contaminated weaning foods [30]. In addition, crawling starts at this age and the risk of ingesting contaminated materials may cause diarrhea. The risk of diarrhea decreases subsequently after 6 - 11 months; this is probably because the children begin to develop immunity to pathogens after repeated exposure [31].

The odds of diarrhea were higher among rural children than urban ones and this was consistent with the findings in Uganda [11] and Egypt [19]. This could be attributed to the fact that the lack of access to water and sanitation facilities in the rural areas was more than in the urban areas [32].

In this study, diarrhea was significantly associated with the presence of two or more under five children in the family. This is in agreement with a study done in Pakistan [33]. Other study also indicated that number of children born was a predictor of diarrhea among under five children [34]. This might be due to the incapability of the caregiver to care for a large number of children [19]. It is possible to suggest that child birth spacing might have a positive influence on prevention of diarrhea.

In conclusion, childhood diarrhea remains an important health concern in the study community. Occurrence of diarrhea could be decreased by interventions aimed to improve sanitation, hygiene and child birth spacing.

\section{ACKNOWLEDGEMENTS}

The authors would like to thank Haramaya University for its finan- cial support. We are also thankful for study participants, data collectors and supervisors for their devotion and full participation.

\section{REFERENCES}

[1] Black, R.E., Morris, S.S. and Bryce. J. (2003) Where and why are 10 million children dying every year? Lancet, 361, 2226-2234. http://dx.doi.org/10.1016/S0140-6736(03)13779-8

[2] Fisher Walker, L.C., Perin, J., Aryee, J.M., Boschi-Pinto, C. and Black, R.E. (2012) Diarrhea incidence in low- and middle-income countries in 1990 and 2010: A systematic review. BMC Public Health, 12. http://dx.doi.org/10.1186/1471-2458-12-220

[3] UNICEF/WHO (2009) Diarrhoea: Why children are still dying and what can be done. The United Nations Children's Fund/World Health Organization, Geneva.

[4] WHO (2007) Combating waterborne disease at the household level. International Network to Promote Household Water Treatment and Safe Storage, World Health Organization, Geneva.

[5] Desalegn, M., Kumie, A. and Tefera, W. (2011) Predictors of under-five childhood diarrhea: Mecha District, West Gojjam, Ethiopia. Ethiopian Journal of Health Development, 25, 174-232.

[6] Teklemariam, S., Getaneh, T. and Bekele, F. (2000) Environmental determinants of diarrheal morbidity in underfive children, Keffa-Sheka zone, south west Ethiopia. Ethiopian Medical Journal, 38, 27-34.

[7] Mediratta, P.R., Feleke, A., Moulton, H.L., Yifru, S. and Sack, B.R. (2010) Risk factors and case management of acute diarrhoea in North Gondar zone, Ethiopia. Journal of Health, Population and Nutrition, 28, 253-263.

[8] Mekasha, A. and Tesfahun, A. (2003) Determinants of diarrhoeal diseases: A community based study in urban south western Ethiopia. East African Medical Journal, 80, 77-82.

[9] Boadi, K.O. and Kuitunen, M. (2005) Childhood diarrheal morbidity in the Accra Metropolitan Area, Ghana: Socio-economic, environmental and behavioral risk determinants. Journal of Health \& Population in Developing Countries. http://www.jhpdc.unc.edu/

[10] Siziya, S., Muula, A.S. and Rudatsikira, E. (2009) Diarrhoea and acute respiratory infections prevalence and risk factors among under-five children in Iraq in 2000. Italian Journal of Pediatrics, 35. http://dx.doi.org/10.1186/1824-7288-35-8

[11] Bbaale, E. (2011) Determinants of diarrhoea and acute respiratory infection among under-fives in Uganda. Australasian Medical Journal, 4, 400-409. http://dx.doi.org/10.4066/AMJ.2011.723

[12] Chopra, M., Mason, E., Borrazzo, J., Campbell, H., Rudan, I., Liu, L., Black, R.E. and Bhutta, Z.A. (2013) Ending of preventable deaths from pneumonia and diarrhoea: An achievable goal. The Lancet, 381, 1499-1506. http://dx.doi.org/10.1016/S0140-6736(13)60319-0

[13] Kersa, D.H.O. (2011) Health service coverage. Kersa 
District Health Office, Eastern Hararge, Ethiopia.

[14] Kelsey, J.L., Whittemore, A.S., Evans, A.S. and Thompson, W.D. (1996) Methods of sampling and estimation of sample size. In: Kelsey, J.L., Whittemore, A.S., Evans, A.S. and Thompson, W.D., Eds., Methods in Observational Epidemiology, Oxford University Press, New York.

[15] CSA (2006) Ethiopian demographic and health survey 2005 Report. Central Statistics Authority, Addis Ababa.

[16] WHO (2005) The treatment of diarrhea. A manual for physicians and other senior health workers. World Health Organization, Geneva.

[17] WHO/UNICEF (2010) Progress on sanitation and drinking-water: 2010 update. World Health Organization/ United Nation Children's Fund, Geneva.

[18] Vyas, S. and Kumaranayake, L. (2006) Constructing socioeconomic status indices: How to use principal components analysis. Health Policy Planning, 21, 459-468. http://dx.doi.org/10.1093/heapol/czl029

[19] El-Gilany, A.H. and Hammad, S. (2005) Epidemiology of diarrhoeal diseases among children under age 5 years in Dakahlia, Egypt. Eastern Mediterranean Health Journal, 11, 762-775

[20] Stanly, A.M., Sathiyasekaran, B.W.C. and Palani, G. (2009) A population based study of acute diarrhoea among children under 5 years in a rural community in South. Sri Ramachandra Journal of Medicine, 1, 1-7.

[21] Rego, R.F., Moraes, L.R. and Dourado, I. (2005) Diarrhoea and garbage disposal in Salvador, Brazil. Royal Society of Tropical Medicine and Hygiene, 99, 48-54. http://dx.doi.org/10.1016/j.trstmh.2004.02.008

[22] Regassa, G., Birke, W., Deboch, B. and Belachew, T. (2008) Environmental determinants of diarrhea among underfive children in Nekemte town, Western Ethiopia. Ethiopian Journal of Health Sciences, 18, 39-45.

[23] Root, G.P.M. (2001) Sanitation, community environment and childhood diarrhea in rural Zimbabwe. Journal of Health, Population and Nutrition, 19, 73-82.

[24] Punyaratabandhu, P., Sangchai, R. and Vathanophas, K. (1993) Risk factors for childhood diarrhoeal diseases in an urban community, Bangkok, Thailand. Journal of the Medical Association of Thailand, 76, 535-541.
[25] Mirza, N.M., Caulfield, L.E. and Black, R.E. (1997) Risk factors for diarrhoeal diseases duration. American Journal of Epidemiology, 146, 776-785. http://dx.doi.org/10.1093/oxfordjournals.aje.a009354

[26] Strina, A., Cairncross, S., Barreto, L.M., Larrea, C. and Prado, S.M. (2003) Childhood diarrhea and observed hygiene behavior in Salvador, Brazil. American Journal of Epidemiology, 157, 1032-1038. http://dx.doi.org/10.1093/aje/kwg075

[27] Manun'ebo, M.N. (1994) Influence of demographic, socioeconomic and environmental variables on childhood diarrhoea in a rural area of Zaire. Journal of Tropical Medicine and Hygiene, 97, 31-38.

[28] Manun'ebo, M., Cousens, S. and Haggerty, P. (1997) Measuring hygiene practices: A comparison of questionnaires with direct observations in rural Zaire. Tropical Medicine and Internal Health, 2, 1015-1021. http://dx.doi.org/10.1046/j.1365-3156.1997.d01-180.x

[29] Halder, A.K., Tronchet, C., Akhter, S., Bhuiya, A., Johnston, R. and Luby, S.P. (2010) Observed hand cleanliness and other measures of handwashing behavior in rural Bangladesh. BMC Public Health, 10. http://dx.doi.org/10.1186/1471-2458-10-545

[30] Dewey, K.G. and Adu-Afarwuah, S. (2008) Systematic review of the efficacy and effectiveness of complementary feeding interventions in developing countries. Maternal \& Child Nutrition, 4, 24-85. http://dx.doi.org/10.1111/j.1740-8709.2007.00124.x

[31] Motarjemi, Y., Käferstein, F., Moy, G. and Quevedo, F. (1993) Contaminated weaning food: A major risk factor for diarrhoea and associated malnutrition. Bulletin of the World Health Organization, 71, 79-92.

[32] WHO/UNICEF (2012) Progress on sanitation and drinking-water: 2010 update. World Health Organization, Geneva.

[33] Shah, M.S., Yousafzai, M., Lakhani, B.N., Chotanp, A.R. and Nowshad, G. (2003) Prevalence and correlates of diarrhea. Indian Journal of Pediatrics, 70, 207-211.

[34] Arif, A. and Naheed, R. (2012) Socio-economic determinants of diarrhoea morbidity in Pakistan. Academic Research International, 2, 398-432. 